ITC $4 / 48$

Information Technology and Control

Vol. 48/ No. 4/ 2019

pp. 648-659

DOI 10.5755/j01.itc.48.4.20590
Fuzzy-Logic-Based Adaptive Proportional-Integral Sliding Mode Control for

Active Suspension Vehicle Systems: Kalman Filtering Approach

\title{
Fuzzy-Logic-Based Adaptive
} Proportional-Integral Sliding Mode Control for Active Suspension Vehicle Systems: Kalman Filtering Approach

\section{Kazem Zare, Mohammad Mehdi Mardani}

Department of Electrical and Electronics Engineering, Shiraz University of Technology, Shiraz, Iran

\section{Navid Vafamand, Mohammad Hassan Khooban}

Department of Engineering, Aarhus University, Aarhus, Denmark

\section{Sajjad Shamsi Sadr}

Department of Mechanical Engineering, Khorramabad University, Khorramabad, Iran

\section{Tomislav Dragičević}

Department of Energy Technology, Aalborg University, Aalborg, Denmark

Corresponding author: sajad_sader@yahoo.com

This paper deals with the problem of synthesizing a fuzzy-logic-based adaptive proportional-integral sliding mode control (FAPISMC) for active suspension systems based on Kalman filtering approach. To improve the performance of the controller and eliminate the effect of the chattering, the switching input is designed based on the fuzzy-logic-based approach with a minimum number of rules. In order to facilitate the stability analysis, the estimation of the state variables is used in designing the sliding surface platform. Furthermore, the gain of the controller is updated by an adaptive law to avoid any pre-knowledge of the disturbance amplitude. Subsequently, the proposed approach is more implementable in real-world processes. Finally, in order to illustrate 
the effectiveness and merits of the proposed approach, a suspension system is considered and simulated by the real-time hardware-in-the-loop (HiL). In this example, a quarter-car model of suspension systems is considered. Then, the obtained real-time results are compared with the linear quadratic regulator approach.

KEYWORDS: Fuzzy-logic-based, Sliding mode control, Kalman filtering, Suspension vehicle systems, hardware-in-the-loop (HiL).

\section{Introduction}

In recent years, several researchers have been attracted to synthesize a suitable controller for suspension systems [26, 48, 9]. Generally, the suspension systems are split into three categories: passive, semi-active, and active [16, 49]. The passive suspensions are composed of spring and damper elements and for normal operation conditions, their performance is fixed. The passive suspension system limits the motion of the body and wheel by limiting their relative velocities to a rate that gives the required ride comfort. From the conventional passive point of view, there exist some tradeoffs between the body vibration and stability of the suspension systems [16]. However, this issue can be handled by the active suspension system scheme [16]. Hence, the active suspension systems have many advantages over the conventional passive ones, such as: increasing the degree of comfortable riding, increasing the car safety, and also improving the comfortable driving $[29,12]$. In the active suspension system, the control mechanism must guarantee the regulation of suspension and body movements as well as the elimination of force disturbances. Therefore, the body movements should be isolated from any incoming disturbances $[29,16]$.

Sliding mode controller (SMC) has been attracting lots of attention during recent years [44, 45, 46, $21,34]$. In order to design an SMC, mainly two steps are considered $[8,22,10]$. The first step is to design a sliding surface such that the desired performance has been guaranteed in a finite time. The second step is to design a controller to force the state variables to reach the sliding surface in a finite time and maintain the state variables on the sliding surface. Some of the main advantages of the SMC can be enumerated as disturbance rejection, insensitivity to parameters uncertainties, fast response, and finite time performance $[25,36,35]$. However, the SMC provides a discontinuous control input signal which is not applicable in practice [20]. One of the fruitful ways to overcome the chattering phenomenon is utilizing the fuzzy approaches together with the SMC [21, 44, 39, 37].

In most of the real world processes, the state variables are not available. Using sensors to measure the state variables is expensive and/or impossible in some situations. Whereas the system output is measured with the additive white noise, the Kalman filter $(\mathrm{KF})$ is used to estimate the state variables based on input-output data [1, 31, 41]. The $\mathrm{KF}$ is well-known as the best linear unbiased estimator. During recent years, there exist flurry of research topics on controlling the active suspensions systems such as back-stepping technique [15], optimal state feedback [2], SMC [42], fuzzy control [43], optimal state feedback [5], non-fragile $H_{\infty}$ control [4], linear quadratic Gaussian [3], neural network techniques [48], fuzzy logic control [9], genetic algorithm [26, 6], linear quadratic regulator (LQR) [9, 2], gain scheduling control [13], and PID control [24]. However, the problem of designing fuzzy adaptive proportional-integral sliding mode control (FAPISMC) by estimating the state variables based on the $\mathrm{KF}$ for an active suspension system has not been addressed yet which is the main contribution and idea of this paper.

In this paper, the problem of designing a FAPISMC is investigated such that the performance of the system is guaranteed in the presence of disturbance and noise. The proposed sliding surface has several advantages over the previous ones, such as 1) it is constructed based on the estimated state variables, 2) it increases the applicability and the ability to implement the proposed approach. The integral part of the proposed sliding surface results in decreasing the reaching time to the sliding surface. Several comparisons with newly published approaches are presented in this paper. The obtained results are compared with LQR method and the passive suspension system. Based on the proposed technique, the performance of the controller is guaranteed. Furthermore, the com- 
fortable riding and car safety will be established. In order to evaluate the applicability and effectiveness of the proposed method, it is applied to a suspension system with the quarter-car model through the real-time hardware-in-the-loop (HiL) simulation and the obtained results are compared with the state-ofthe-art methods.

The rest of the paper is organized as follows: Section 2 studies the dynamic model of suspension systems; the $\mathrm{KF}$ is investigated in Section 3; the proposed controller is discussed in Section 4; Section 5 illustrates the simulation and comparison results. Finally, the conclusions are provided in Section 6.

\section{Problem Formulation}

The model of the quarter-car active suspension system utilized in this paper is drawn in Fig. 1, where $m_{s}$ and $m_{u}$ stand for the sprung and unsprung masses, $k_{t}$ and $k_{s}$ are stiffness values for tire and suspension spring, $c_{t}$ and $c_{s}$ are the damping coefficients of the tire and suspension damper, respectively, $u(t)$ stands for the active input of the suspension system, $z_{s}$ and $z_{u}$ denote the displacements of the sprung and unsprung masses, respectively, and $z_{s}$ is the road displacement input. The dynamic equation of the suspension model is established as follows [14]:

$$
\begin{aligned}
& m_{u} \ddot{z}_{u}(t)+c_{s}\left(\dot{z}_{u}(t)-\dot{z}_{s}(t)\right)+k_{s}\left(z_{u}(t)-z_{s}(t)\right) \\
& +c_{t}\left(\dot{z}_{u}(t)-\dot{z}_{r}(t)\right)+k_{t}\left(z_{u}(t)-z_{r}(t)\right)=-u(t), \\
& m_{s} \ddot{z}_{s}(t)+c_{s}\left(\dot{z}_{s}(t)-\dot{z}_{u}(t)\right)+k_{s}\left(z_{s}(t)-z_{u}(t)\right)=u(t) .
\end{aligned}
$$

Let $x_{1}(t)=z_{s}(t)-z_{u}(t)$ denote the suspension deflection, $x_{2}(t)=\dot{z}_{s}(t)$ the car body velocity, $x_{3}(t)=z_{u}(t)-z_{r}(t)$ the tire deflection, $x_{4}(t)=\dot{z}_{u}(t)$ the wheel velocity, and $\omega(t)=\dot{z}_{r}(t)$ the disturbance input.

Equation (1) shows that the disturbance input is not in phase with the actuator input. Therefore, the system suffers from the mismatched condition. Thus, the proposed controller must be robust enough to overcome the mismatched condition so that the disturbance would not have a significant effect on the performance of the system. Equation (1) can be rewritten as:

$$
\begin{aligned}
\dot{x}(t) & =A x(t)+B u(t)+B_{1} \omega(t) \\
& =A x(t)+B u(t)+f(t),
\end{aligned}
$$

\section{Figure 1}

Quarter-car model [14]

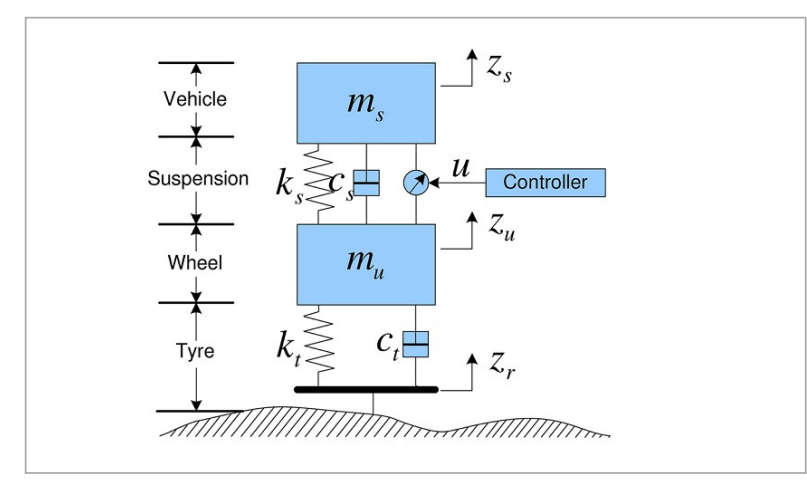

where

$$
\begin{aligned}
A & =\left[\begin{array}{cccc}
0 & 1 & 0 & -1 \\
-\frac{k_{s}}{m_{s}} & -\frac{c_{s}}{m_{s}} & 0 & \frac{c_{s}}{m_{s}} \\
0 & 0 & 0 & 1 \\
\frac{k_{s}}{m_{u}} & \frac{c_{s}}{m_{u}} & \frac{-k_{t}}{m_{u}} & -\frac{c_{s}+c_{t}}{m_{u}}
\end{array}\right], \\
B & =\left[\begin{array}{c}
0 \\
\frac{1}{m_{s}} \\
0 \\
\frac{-1}{m_{u}}
\end{array}\right], B_{1}=\left[\begin{array}{c}
0 \\
0 \\
-1 \\
\frac{c_{t}}{m_{u}}
\end{array}\right],
\end{aligned}
$$

where $x(t) \in R^{4}$ is the state vector, $u(t) \in R$ is the control input, and the continuous function $f(t)$ is the bounded disturbance in the suspension system. Moreover, the measured output vector is defined as below:

$$
y(t)=\left[\begin{array}{c}
z_{s}(t) \\
z_{s}(t)-z_{u}(t) \\
z_{u}(t)-z_{r}(t)
\end{array}\right]=C x(t)+D u(t)
$$

where

$$
C=\left[\begin{array}{cccc}
-\frac{k_{s}}{m_{s}} & -\frac{c_{s}}{m_{s}} & 0 & \frac{c_{s}}{m_{s}} \\
1 & 0 & 0 & 0 \\
0 & 0 & 1 & 0
\end{array}\right], D=\left[\begin{array}{c}
\frac{1}{m_{s}} \\
0 \\
0
\end{array}\right]
$$


The following assumptions are taken as standard.

Assumption 1: The pair $(A, B)$ is controllable and the input matrix $B$ has a full-column rank.

Assumption 2: $\omega(t)$ is a bounded function.

Assumption 3: The pair $(A, C)$ is observable.

With respect to the suspension control application, it is the aim of the observer to estimate the states of the full-scale suspension model. This is done by means of a full-order observer using Kalman filter theory.

\section{Kalman Filter}

For the design of the Kalman filter, consider the following representation [33]:

$$
\begin{aligned}
& \dot{x}(t)=A x(t)+B u(t)+f(t)+G w(t), \\
& y=C x(t)+D u(t)+v(t)
\end{aligned}
$$

where $w(t)$ and $v(t)$ denote the zero-mean Gaussian white process and measurement noises, respectively, characterized by

$$
E\{w(t)\}=0, \quad E\{v(t)\}=0
$$

and

$$
\begin{aligned}
& E\left\{w(t) w^{T}(t)\right\}=Q \delta(t-\tau), \quad Q=Q^{T}>0, \\
& E\left\{v(t) v^{T}(t)\right\}=R \delta(t-\tau), \quad R=R^{T}>0 .
\end{aligned}
$$

In this context, $E\{\cdot\}$ and $\delta(t-\tau)$ represent the expectation value operator and the Dirac delta, respectively. Furthermore, $w(t)$ and $v(t)$ are assumed to be uncorrelated with each other. Based on Equation (6), an optimal state observer, i.e. $K F$, can be constructed as [33]

$$
\begin{aligned}
& \hat{x}(t)=A \hat{x}(t)+B u(t)+L(y-\hat{y}), \\
& \hat{y}=C \hat{x}(t)+D u(t) .
\end{aligned}
$$

where $L$ is the observer gain matrix. The objective of the observer (9) is to eventually converge its states to those of system (6). This is the case if the error dynamic $\dot{e}(t)=\dot{x}(t)-\dot{\bar{x}}(t)$ is asymptotically stable. For the non-perturbed system, the error dynamic yields:

$$
\dot{e}=(A-L C) e .
$$

Since the $K F$ is of the same structure as Equation (9) and due to its optimality properties in case of stochastically disturbed linear systems, the matrix $L$ can be determined based on Kalman filter theory [33], as:

$$
L=P C^{T} R^{-1},
$$

where $P$ is the symmetric and positive definite solution of the algebraic matrix Riccati equation

$$
A P+P A^{T}+G Q G-P C^{T} R^{-1} C P=0 .
$$

\section{Control Problem}

The control objective is to maximize the passenger comfort and minimize the passenger acceleration, under road disturbances. Due to the presence of model disturbances in Equation (2), the fuzzy proportional-integral sliding controller is designed to make the state trajectories converge to zero.

At the first step of the design procedure, we construct an integral-type sliding-surface function as follows:

$$
\sigma=\alpha_{1} \hat{x}+\alpha_{2} \int \hat{x} d t
$$

where $\alpha_{1}$ and $\alpha_{2}$ are two constant vectors. Differentiating Equation (13), along with the state estimation Equation (9) yields

$$
\dot{\sigma}=\alpha_{1}(A \hat{x}(t)+B u(t)+L(y-\hat{y}))+\alpha_{2} \hat{x} .
$$

In order to derive a control law to ensure the closedloop robust stability, the following Lyapunov function candidate is considered $[23,44,46]$ :

$$
V(x)=\frac{1}{2} \sigma^{2} .
$$

Taking the time derivative of Equation (15) and incorporating Equation (14), one can obtain

$$
\dot{V}=\sigma\left(\alpha_{1}(A \hat{x}+B u+L(y-\hat{y}))+\alpha_{2} \hat{x}\right) .
$$

To ensure the closed-loop stability, based on the Lyapunov stability theorem, the control input is determined, such that $V$ is negative definite, i.e $[44,46,23]$ :

$$
\dot{V} \leq-\eta|\sigma|,
$$


where $\eta$ is a positive constant. The control input $u$ is chosen as:

$$
u=u_{e q}-\left(\alpha_{1} B\right)^{-1} k \operatorname{sgn}(\sigma),
$$

where $\alpha_{1}$ is defined in Equation (13) and chosen such that $\alpha_{1} B$ is invertible, $k$ is a positive parameter to be designed, and $\operatorname{sgn}(\cdot)$ represents the sign function. The equivalent control action $u_{e q}$ is obtained by solving $\dot{\sigma}=0$ in Equation (14), in the absence of uncertainties and disturbances, i.e.,

$$
u_{e q}=-\left(\alpha_{1} B\right)^{-1}\left(\alpha_{1}(A-L C) \hat{x}+\alpha_{1} L C x+\alpha_{2} \hat{x}\right) .
$$

By substituting (18) into (16) one obtains

$$
\dot{V}=\sigma\left[\alpha_{1} L v(t)-k \operatorname{sgn}(\sigma)\right] .
$$

In order to satisfy Equation (17), it is sufficient to choose $k \geq\left|\eta+\sigma \alpha_{1} L v(t)\right|$. However, the selection of $k$ is a hard task. Hence, an adaptive tuning law is proposed to determine $k$. Then, the control law (18) can be written as:

$u=-\left(\alpha_{1} B\right)^{-1}\left(\alpha_{1}(A-L C) \hat{x}+\alpha_{1} L C x+\alpha_{2} \hat{x}+\hat{k} \operatorname{sgn}(\sigma)\right)$,

where $\hat{k}$ is the unknown bound, which will be estimated adaptively. To choose the adaptation law for $\hat{k}$ based on the Lyapunov technique, consider the following Lyapunov function:

$$
V=\frac{1}{2} \sigma^{2}+\frac{1}{2} \gamma \tilde{k}^{2},
$$

where $\tilde{k}=\hat{k}-k$ is the adaptive error. By performing the same procedure as given in Equations (16)-(20) to compute the time derivative of the Lyapunov function, one has

$$
\begin{aligned}
\dot{V}= & \sigma \dot{\sigma}+\gamma \tilde{k} \dot{\tilde{k}} \leq \sigma\left[\alpha_{1} L v(t)-\hat{k} \operatorname{sgn}(\sigma)\right] \\
& +(\hat{k}-k)|\sigma| \leq \alpha_{1} L v(t)|\sigma|-k|\sigma| \leq 0
\end{aligned}
$$

Therefore, the adaptation law for the parameter $\hat{k}$ is obtained as:

$$
\dot{\tilde{k}}=\frac{1}{\gamma}|\sigma|
$$

where $\gamma>0$ is the designed positive constant. Moreover, the chattering phenomenon is inevitable due to the existence of sign function in control input $u$. One effective way for chattering reduction is replacing the discontinuous function $\operatorname{sgn}(\cdot)$ with continuous functions [39, 45]. Fuzzy logic controllers are widely utilized to stabilize the systems during recent years [28, $27,38,30,11,40,7,17]$. In this paper, the fuzzy mechanism $u_{f s}$ is employed and incorporated into Equation (20) to form

$$
u=u_{e q}+\left(\alpha_{1} B\right)^{-1} \hat{k} u_{f s} \text {. }
$$

Letting $\sigma$ and $u_{f s}$ be the input and the output variables of the FAPISMC, respectively, the instinctive rules can be written as:

$$
\left\{\begin{array}{lll}
u_{f s}>0 & \text { if } & \sigma<0 \\
u_{f s}=0 & \text { if } & \sigma=0 \\
u_{f s}<0 & \text { if } & \sigma>0
\end{array}\right.
$$

The input and output spaces are fuzzily partitioned into three fuzzy sets. The input and output membership functions are shown in Fig. 2.

\section{Figure 2}

Membership functions of FAPISMC for (a) input, (b) output

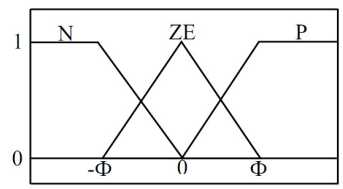

(a)

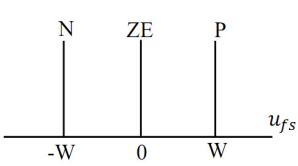

(b)
Table 1

Fuzzy-Rule Base for FAPISMC

\begin{tabular}{l|lcc}
\hline $\operatorname{Input}(\sigma)$ & $\mathrm{N}$ & $\mathrm{ZE}$ & $\mathrm{P}$ \\
\hline $\operatorname{Output}\left(u_{f s}\right)$ & $\mathrm{P}$ & $\mathrm{ZE}$ & $\mathrm{N}$ \\
\hline
\end{tabular}

Labels of the input and output membership functions are $\mathrm{N}$ (negative), ZE (zero), and P (positive), with $\Phi$ and $\mathrm{W}$ as two real constants. As summarized in Table 1, the ith fuzzy rule for the system takes the following form:

$R_{i}: I F \sigma i s F_{\sigma}^{l} T H E N u_{f s}$ is $F_{u_{s s}}^{l}, i=1,2,3$, (27) 
where $F_{\sigma}^{i}$ and $F_{u_{s}}^{i}$ are the corresponding fuzzy sets, defined based on Equation (27).

By using the centroid-defuzzification technique, the output $u_{f s}$ is calculated as:

$$
u_{f s}=\frac{\sum_{i=1}^{3} g_{\sigma}^{i} F_{\sigma}^{i}(\sigma)}{\sum_{i=1}^{3} F_{\sigma}^{i}(\sigma)},
$$

where $g_{\sigma}^{i} \in\{-W, 0, W\}, i=1,2,3$ are the values of the corresponding output fuzzy singletons $[19,18]$.

\section{Simulation Results}

In order to evaluate the performance of the proposed control method, the Hardware-In-the-Loop (HiL) simulation approach is utilized. The real-time HiL method is used to emulate errors and delays that do not exist in the classical off-line simulations. The HiL setup is illustrated in Fig. 3 and is consisting of: I) OPAL-RT as a real-time simulator (RTS); II) a PC as the command station (programming host) in which the Matlab/Simulink based code executed on the OPAL-RT is generated, and III) a router used as a connector of all the setup devices in the same sub-network. The OPAL-RT is also connected to the DK60 board through Ethernet ports [47]. The mathematical model of the system as defined in Equation (2) and the proposed proportional-integral sliding mode controller based on Kalman filter in Equation (21) are simulated on a computer, and the estimation performance of the Kalman filter is analyzed in the simulation.

\section{Figure 3}

The real-time experimental setup

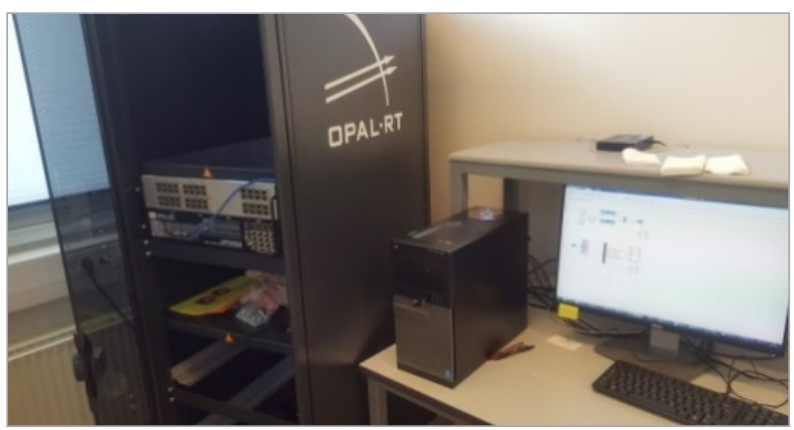

A measurement of a real rough country road profile traveled at a vehicle speed of $V=50 \mathrm{~km} / \mathrm{h}$ serves as the road excitation. The road height profile and power spectral density of the generic highway road are given in Fig. 4 and Fig. 5, respectively.

Figure 4

Height profile $z_{r}$ at $V=50 \mathrm{~km} / \mathrm{h}$

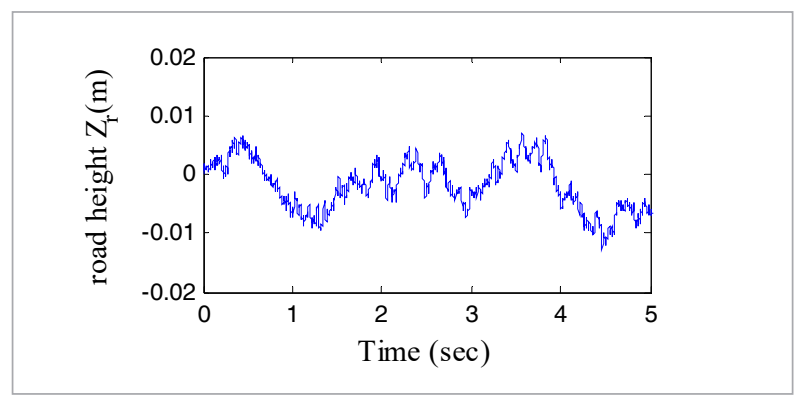

Figure 5

Power spectral density of generic highway road at $V=50 \mathrm{~km} / \mathrm{h}$

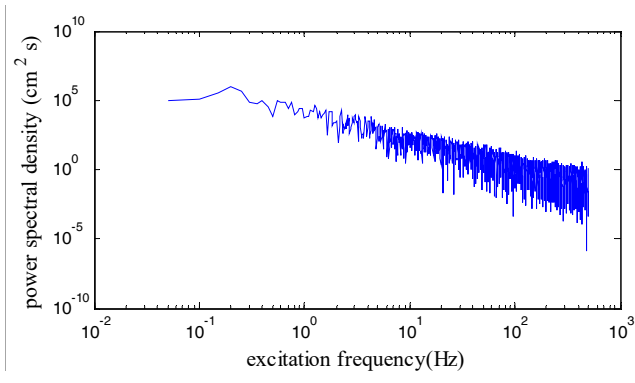

Also, a bump road running condition is used to evaluate the proposed method effect. Considering the case of an isolated bump in an otherwise smooth road surface, the corresponding road displacement input of the vehicle model is presented as:

$$
Z_{r}= \begin{cases}0, & \text { if } 0 \leq t \leq 0.5 \\ \frac{A}{2}\left(1-\cos \left(\frac{2 \pi V}{L}(t-0.5)\right)\right), & \text { if } 0.5 \leq t \leq \frac{L}{V}, \\ 0, & \text { if } t>\frac{L}{V}\end{cases}
$$

where $A$ and $L$ are the height and the length of the bump, respectively. We choose $A=0.1 \mathrm{~m}, L=2.5 \mathrm{~m}$, and the vehicle forward velocity as $V=50 \mathrm{~km} / \mathrm{h}$. According to Equation (29), the corresponding $z_{r}$ curve under a bump road running condition is shown in Fig. 6 .

For comparison purposes, the performance of the proposed controller is compared to the LQR control 
Figure 6

$z_{r}$ curve under the bump road running condition at $V=50 \mathrm{~km} / \mathrm{h}$

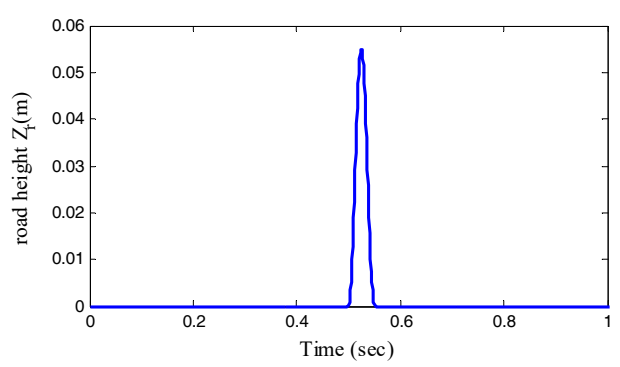

approach [32]. In this method, a quadratic performance index of the form $J=\frac{1}{2} \int_{0}^{\infty}\left(x^{T} R_{1} x+u^{T} R_{2} u\right) d t$ is considered, where the matrix $R_{1}$ is symmetric positive semi-definite and $R_{2}$ is symmetric positive definite.

Then, the optimal linear feedback control law is obtained as:

$u=-k x$

where $k$ is the designed matrix gain. Numerical values for the model parameters are listed in Table 2 [49].

Table 2

Parameters needed in model

\begin{tabular}{c|c|c}
\hline Parameter & Value & Unit \\
\hline$M_{s}$ & 290 & $K g$ \\
\hline$M_{u s}$ & 59 & $K g$ \\
\hline$K_{a}$ & 16812 & $N / m$ \\
\hline$K_{t}$ & 190000 & $N / m$ \\
\hline$C_{a}$ & 1000 & $N /(m / s)$ \\
\hline
\end{tabular}

The sliding coefficients in the proposed controller are selected as $\alpha_{1}=\left[\begin{array}{llll}5 & 0.1 & 0.1 & 0.01\end{array}\right]$ and $\alpha_{2}=$ $\left[\begin{array}{llll}0.2 & .01 & 0.2 & 0.01\end{array}\right]$. The parameters used in the input fuzzy sets $w=1$ and $\Phi=0.09$ are simply determined to partition the suitable region. In the design of the LQR controller, weighting matrices $Q$ and $R$ are selected as $Q=\operatorname{diag}\left[10^{4} ; 10^{4} ; 10^{4} ; 10^{4}\right]$ and $R=10^{-4}$. Consequently, the designed gains of the LQR controller are [3]: $k_{1}=2750, k_{2}=9720, k_{3}=-206400$, and $k_{4}=8240$.

The simulation results are plotted in Figs. 7-9. From Figs. 7 and 9, it is evident that the KF can effectively estimate the suspension state variables when the vehicle is driving on the random road. Fig. 8 shows how
Figure 7

KF performance under height profile road

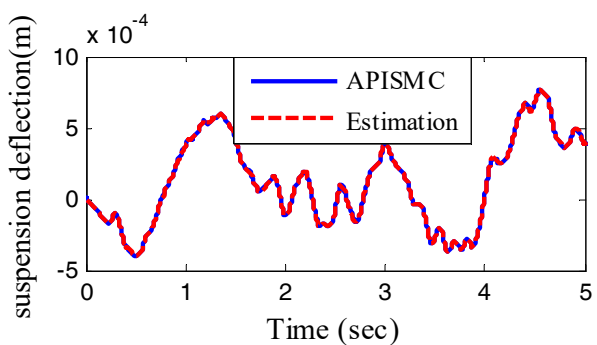

(a)

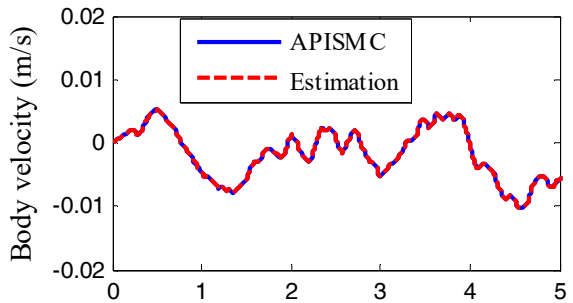

(b)

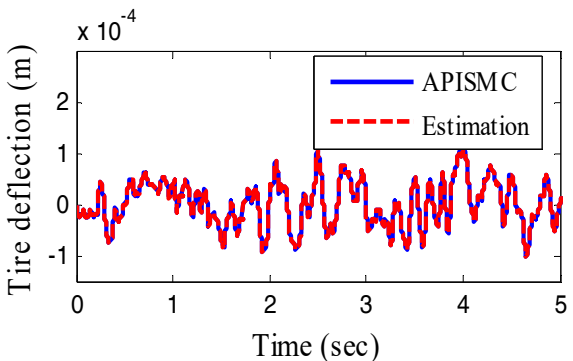

(c)

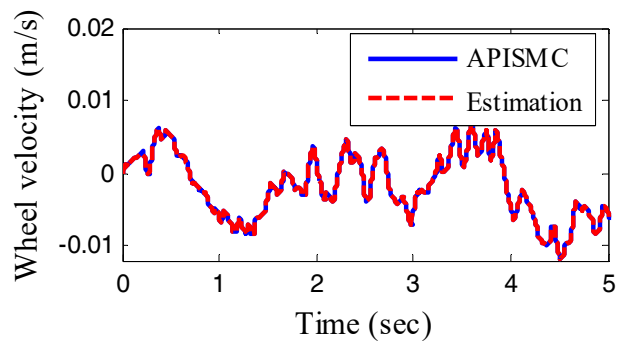

(d)

the adaptive gain parameter changes.

Fig. 9 illustrates clearly how the FAPISMC can effectively absorb the vehicle vibration in comparison to the LQR method and the passive system. The body acceleration in the FAPISMC design system is reduced 
Figure 8

The adaptive gain parameter for the height profile road

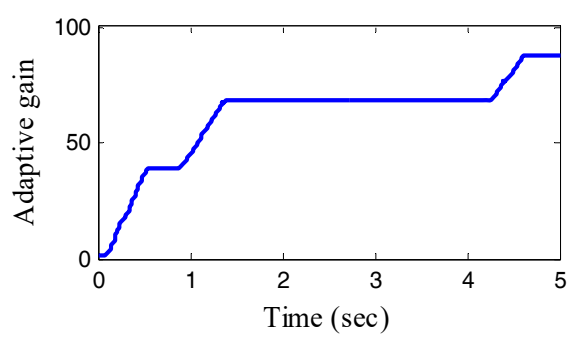

Figure 9

Proposed method performance under height profile road

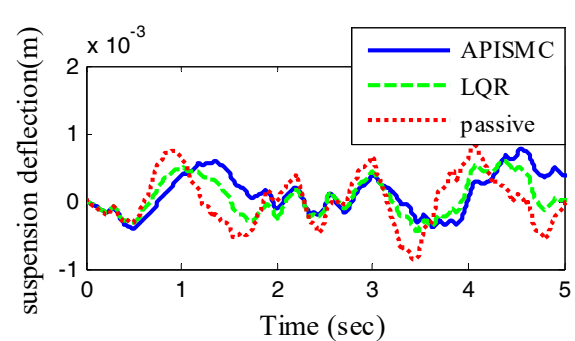

(a)

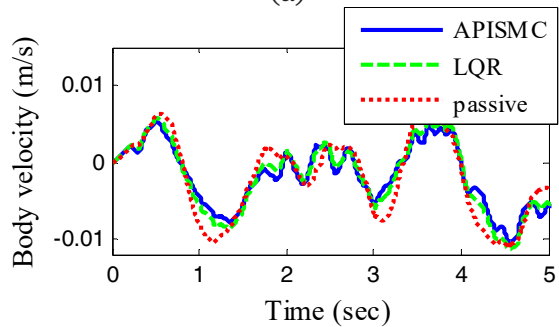

(b)

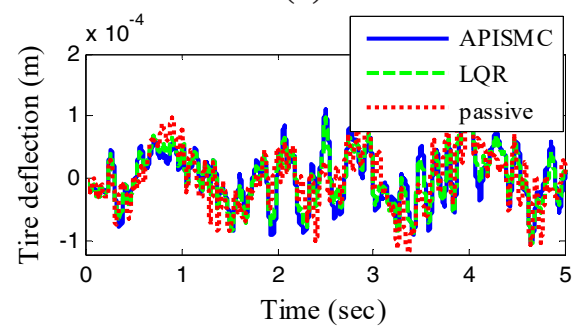

(c)

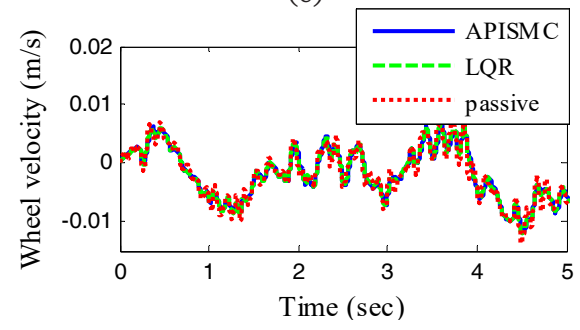

(d) significantly, which guarantees better ride comfort. Moreover, the wheel deflection is also smaller using the proposed controller. Therefore, it is concluded that the active suspension system with the FAPISMC improves the ride comfort while retaining the road handling characteristics, as compared to the $\mathrm{LQR}$ method and the passive suspension system. The result shows that the active suspension utilizing the FAPISMC technique performs better as compared to the others.

The simulation results for bump road running condition are plotted in Figs. 10 and 11.

Figure 10

Proposed method performance under bump road

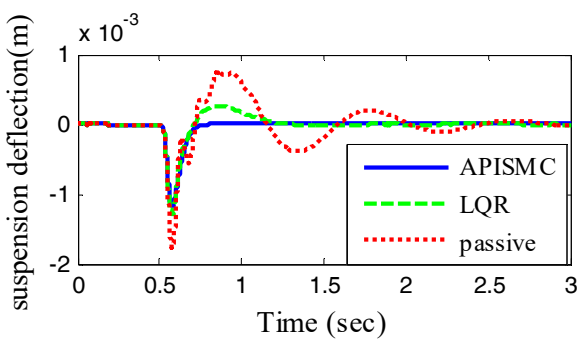

(a)

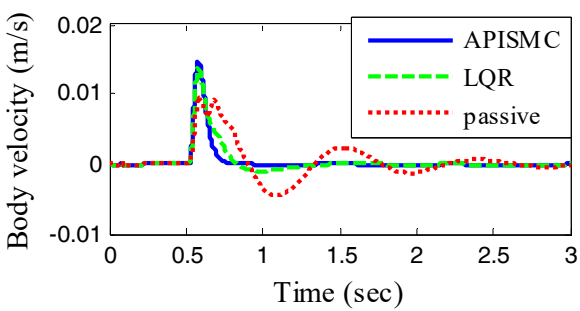

(b)

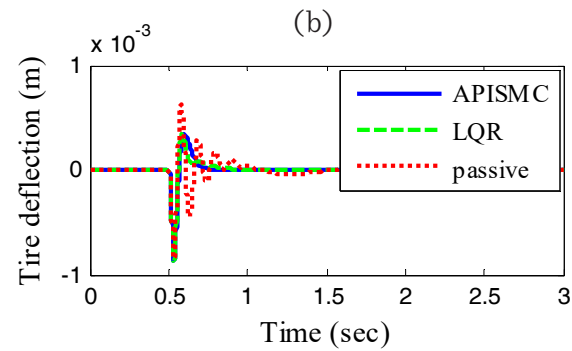

(c)

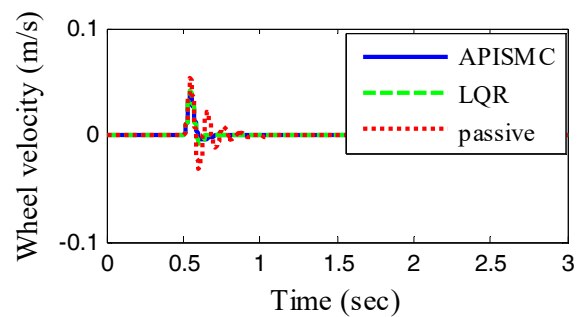

(d) 
Figure 11

The adaptive gain parameter for the bump

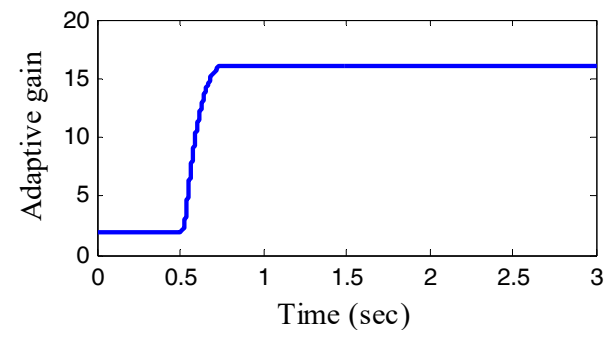

Fig. 10 illustrates clearly how the FAPISMC can effectively absorb the vehicle vibration in comparison to the LQR method and the passive system. It is evident that the KF can effectively estimate the suspension state variables when the vehicle is driving on the bumpy road. Fig. 11 shows how the adaptive gain parameter changes.

It can be concluded that compared with the LQR and passive suspension system, the proposed method could have a good performance despite the random road and bumpy road. The efficiency of the LQR, passive and the proposed control schemes are evaluated by three common error measurement criteria, i.e., the sum of the squared errors (SSE), mean absolute error (MAE), and mean square error (MSE). In brief, these approaches will yield an optimal performance if the values of SSE, MAE, and MSE are close to zero. Table 3 shows the evaluation results for three controllers.

\section{Table 3}

Comparison performance of the proposed method with other controllers

\begin{tabular}{c|c|c|c}
\hline Criteria & LQR & passive & Prop. Method \\
\hline SSE & 7.5310 & 6.5891 & 1.5043 \\
\hline MAE & 0.0819 & 0.0610 & 0.0147 \\
\hline MSE & $9.9410 \mathrm{e}-4$ & $5.9982 \mathrm{e}-4$ & $0.9901 \mathrm{e}-4$ \\
\hline
\end{tabular}

Remark 1: The results in Case 2 show that when the system works under a bumpy road, the LQR and pas- sive controllers can still work but their performance is not optimal. When the system works under height profile road, these controllers may not stabilize the system. However, the proposed method has a better performance than the LQR and passive controllers. The FAPISMC controller can achieve control goals in a faster responding and smoother manner. The test results in Cases 1 and 2 demonstrate the excellent robust performance of the designed controller. As it is clearly seen in Figs. 9 and 10, the LQR controller and the passive controller do not have a good response against the severe disturbance input.

\section{Conclusion}

The purpose of this study is to design the FAPISMC for active suspension systems, despite the external impedance of the system entered into the system. Given that the proportional-integral-controller and the fuzzy controllers for such systems do not work well lonely, these approaches are usually not used for such systems. The improved sliding mode technique has been considered in this study, due to its resistance to external and internal disturbances. One of the methods of sliding mode control is the fitting-integral sliding surface, which has many advantages over classic sliding mode, including 1) an additional design parameter gives more freedom to design proportional-integral sliding mode control, 2) tracking arbitrary signals using this type of controller can be developed, 3) For the systems that have high offsets or steady-state errors, they provide better performance.

In addition, the gain of the controller is updated by an adaptive law to avoid any pre-knowledge of the disturbance amplitude. Therefore, the adoption of the Kalman filter strategy will not only improve the performance of the proposed controller but will also make it more comfortable for the occupants of the car and improve driving quality. The globally asymptotic stability of the closed-loop system is mathematically proved. Finally, in order to validate the feasibility of the suggested approach under load disturbances, detailed simulation, and hardware-inthe-loop experimental results are shown. 


\section{References}

1. Acosta, M. Kanarachos, S. Tire Lateral Force Estimation and Grip Potential Identification Using Neural Networks, Extended Kalman Filter, and Recursive Least Squares. Neural Computing and Applications, 2017, 30(11), 1-21. https://doi.org/10.1007/s00521-017-2932-9

2. Alleyne, A., Hedrick, J. K. Nonlinear Adaptive Control of Active Suspensions. IEEE transactions on control systems technology, 1995, 3(1), 94-101. https://doi. org/10.1109/87.370714

3. Brezas, P., Smith, M. C. Linear Quadratic Optimal and Risk-Sensitive Control for Vehicle Active Suspensions. IEEE Transactions on Control Systems Technology, 2014, 22(2), 543-556. https://doi.org/10.1109/ TCST.2013.2253556

4. Du, H., Lam, J., Sze, K. Y. Design of Non-Fragile $\mathrm{H}_{\infty}$ Controller for Active Vehicle Suspensions. Journal of Vibration and Control, 2005, 11(2), 225-243. https://doi. org/10.1177/1077546305049392

5. Esmailzadeh, E., Taghirad, H. Active Vehicle Suspensions with Optimal State-Feedback Control. International Journal of Modelling and Simulation, 1998, 18(3), 228238. https://doi.org/10.1080/02286203.1998.11760383

6. Feng, J., Matthews, C., Zheng, S., Yu, F., Gao, D. Hierarchical Control Strategy for Active Hydropneumatic Suspension Vehicles Based on Genetic Algorithms. Advances in Mechanical Engineering, 2015, 7(2), 1-10. https://doi.org/10.1155/2014/951050

7. Ghavidel, H. F., Kalat, A. A. Observer-Based Hybrid Adaptive Fuzzy Control for Affine and Nonaffine Uncertain Nonlinear Systems. Neural Computing and Applications, 2018, 30(4), 1187-1202. https://doi. org/10.1007/s00521-016-2732-7

8. Hamza, M.F., Yap, H. J., Choudhury, I. A., Chiroma, H., Kumbasar, T. A Survey on Advancement of Hybrid Type 2 Fuzzy Sliding Mode Control. Neural Computing and Applications, 2018, 30(2), 331-353. https://doi. org/10.1007/s00521-017-3144-z

9. Hasbullah, F., Faris, W. F. A Comparative Analysis of LQR and Fuzzy Logic Controller for Active Suspension Using Half Car Model. Control Automation Robotics \& Vision (ICARCV), 11th International Conference on IEEE, 2010, 2415-2420. https://doi.org/10.1109/ICARCV.2010.5ror260

10. Khooban, M. H., Niknam, T., Blaabjerg, F., Dehghani, M. Free Chattering Hybrid Sliding Mode Control for a Class of Non-Linear Systems: Electric Vehicles As a Case Study. IET Science, Measurement \& Technology, 2016, 10(7), 776-785. https://doi.org/10.1049/ietsmt.2016.0091

11. Khooban, M. H., Vafamand, N., Liaghat, A., Dragicevic, T. An Optimal General Type-2 Fuzzy Controller for Urban Traffic Network. ISA Transactions, 2017, 66, 335343. https://doi.org/10.1016/j.isatra.2016.10.011

12. Khooban, M. H., Vafamand, N., Niknam, T., Dragicevic, T., Blaabjerg, F. Model-Predictive Control Based on Takagi-Sugeno Fuzzy Model for Electrical Vehicles Delayed Model. IET Electric Power Applications, 2017, 11(5), 918-934. https://doi.org/10.1049/ietepa.2016.0508

13. Kim, M.-S., Byun, Y.-S., Lee, Y.-H., Lee, K.-S. Gain Scheduling Control of Levitation System in Electromagnetic Suspension Vehicle. WSEAS Transactions on Circuits and Systems, 2006, 5(12), 1706-1712.

14. Li, H., Jing, X., Lam, H.-K., Shi, P. Fuzzy Sampled-Data Control for Uncertain Vehicle Suspension Systems. IEEE Transactions on Cybernetics, 2014, 44(7), 11111126. https://doi.org/10.1109/TCYB.2013.2279534

15. Lin, J.-S., Kanellakopoulos, I. Nonlinear Design of Active Suspensions. 34th IEEE Conference on Proceedings of the Decision and Control, 1995, 3567-3569.

16. Liu, H., Gao, H., Li, P. Handbook of Vehicle Suspension Control Systems. Institution of Engineering and Technology, 2013.

17. Mardani, M. M., Vafamand, N., Shokrian Zeini, M., Shasadeghi, M. Sum-of-Squares-Based Finite-Time Adaptive Sliding Mode Control of Uncertain Polynomial Systems with Input Nonlinearities. Asian Journal of Control, 2018, 20(4), 1658-1662. https://doi. org/10.1002/asjc.1625

18. Mardani, M. M., Vafamand, N., Khooban, M. H., Dragicevic, T., Blaabjerg, F. Design of Quadratic D-Stable Fuzzy Controller for DC Microgrids with Multiple CPLs. IEEE Transactions on Industrial Electronics, 2019, 66(6), 4805-4812. https://doi.org/10.1109/TIE.2018.2851971

19. Mardani, M. M., Vafamand, N., Khooban, M. H., Dragicevic, T., Blaabjerg, F. Non-Fragile Controller Design of Uncertain Saturated Polynomial Fuzzy Systems Subjected to Persistent Bounded Disturbance. Transactions of the Institute of Measurement and Control, 2019, 41(3), 842-858. https://doi.org/10.1177//0142331218774110 
20. Mardani, M. M., Shasadeghi, M., Safarinejadian, B. Design of Distributed Sampled-Data Fuzzy Controller for a Class of Non-Linear Hyperbolic PDE Systems: Input Delay Approach. IET Control Theory \& Applications, 2018, 12(6), 728-737. https://doi.org/10.1049/ iet-cta.2017.0915

21. Meghni, B., Dib, D., Azar, A. T. A Second-Order Sliding Mode and Fuzzy Logic Control to Optimal Energy Management in Wind Turbine with Battery Storage. Neural Computing and Applications, 2017, 28(6), 14171434. https://doi.org/10.1007/s00521-015-2161-z

22. Mobayen, S. Design of LMI-Based Sliding Mode Controller with an Exponential Policy for a Class of Underactuated Systems. Complexity, 2016, 21(5), 117-124. https://doi.org/10.1002/cplx.21636

23. Mobayen, S., Tchier, F. Design of an Adaptive Chattering Avoidance Global Sliding Mode Tracker for Uncertain Non-Linear Time-Varying Systems. Transactions of the Institute of Measurement and Control, 2017, 39(10), 1547-1558. https://doi.org/10.1177/0142331216644046

24. Mouleeswaran, S. Design and Development of PID Controller-Based Active Suspension System for Automobiles. INTECH Open Access Publisher, 2012. https://doi. org/10.5772/32611

25. Niknam, T., Khooban, M. H., Kavousifard, A., Soltanpour, M. R. An Optimal Type II Fuzzy Sliding Mode Control Design for a Class of Nonlinear Systems. Nonlinear Dynamics, 2014,75(1-2), 73-83.https://doi.org/10.1007/ s11071-013-1050-1

26. Nourisola, H. Ahmadi, B. Robust Adaptive Hœ Controller Based on GA-Wavelet-SVM for Nonlinear Vehicle Suspension with Time Delay Actuator. Journal of Vibration and Control, 2016, 22(20), 4111-4120. https:// doi.org/10.1177/10777546315571445

27. Pitarch, J., Rakhshan, M., Mardani, M. M., Sadeghi, M., de Prada, C. Distributed Nonlinear Control of a PlugFlow Reactor Under Saturation. IFAC-PapersOnLine, 2016, 49(24), 87-92. https://doi.org/10.1016/j.ifacol.2016.10.760

28. Pitarch, J. L., Rakhshan, M., Mardani, M. M., Sadeghi, M. Distributed Saturated Control for a Class of Semilinear PDE Systems: A SOS Approach. IEEE Transactions on Fuzzy Systems, 2018, 26(2), 749-760. https://doi. org/10.1109/TFUZZ.2017.2688379

29. Pletschen, N., Diepold, K. J. Nonlinear State Estimation for Suspension Control Applications: A Takagi-Sugeno Kalman Filtering Approach. Control Engineering Practice, 2017, 61, 292-306. https://doi.org/10.1016/j. conengprac.2016.05.013
30. Sadeghi, M. S., Vafamand, N. More Relaxed Stability Conditions for Fuzzy TS Control Systems by Optimal Determination of Membership Function Information. Journal of Control Engineering and Applied Informatics, 2014, 16(2), 67-77\%.

31. Safarinejadian, B. Vafamand, N. Kalman Randomized Joint UKF Algorithm for Dual Estimation of States and Parameters in a Nonlinear System. Journal of Electrical Engineering and Technology, 2015, 10(3), 12121220. https://doi.org/10.5370/JEET.2015.10.3.1212

32. Sam, Y. M., Osman, J. H., Ghani, M. R. A. A Class of Proportional-Integral Sliding Mode Control with Application to Active Suspension System. Systems \& Control Letters, 2004, 51(3), 217-223. https://doi.org/10.1016/j. sysconle.2003.08.007

33. Simon, D. Optimal State Estimation: Kalman, H Infinity, and Nonlinear Approaches. John Wiley \& Sons, 2006. https://doi.org/10.1002/0470045345

34. Soltanpour, M. R., Khooban, M. H., Khalghani, M. R. An Optimal and Intelligent Control Strategy for a Class of Nonlinear Systems: Adaptive Fuzzy Sliding Mode. Journal of Vibration and Control, 2016, 22(1), 159-175. https://doi.org/10.1177/1077546314526920

35. Soltanpour, M. R., Khooban, M. H., Soltani, M. Robust Fuzzy Sliding Mode Control for Tracking the Robot Manipulator in Joint Space and in Presence of Uncertainties. Robotica, 2014, 32(3), 433-446. https://doi. org/10.1017/S0263574713000702

36. Soltanpour, M. R., Otadolajam, P., Khooban, M. H. Robust Control Strategy for Electrically Driven Robot Manipulators: Adaptive Fuzzy Sliding Mode. IET Science, Measurement \& Technology, 2015, 9(3), 322-334. https://doi.org/10.1049/iet-smt.2013.0265

37. Soltanpour, M. R., Zolfaghari, B., Soltani, M., Khooban, M. H. Fuzzy Sliding Mode Control Design for a Class of Nonlinear Systems with Structured and Unstructured Uncertainties. International Journal of Innovative Computing, Information and Control, 2013, 9(7), 2713-2726.

38. Tabari Saadi, P., Mardani, M. M., Shasadeghi, M., Safarinejadian, B. Leader-Following Consensus of Nonlinear Multi-Agent Systems Based on Parameterized Lyapunov Function. The Modares Journal of Electrical Engineering, 2015, 15(2), 30-35.

39. Tao, C.-W., Taur, J.-S., Chang, Y.-H., Chang, C.-W. A Novel Fuzzy-Sliding and Fuzzy-Integral-Sliding Controller for the Twin-Rotor Multi-Input-Multi-Output System. IEEE Transactions on Fuzzy Systems, 2010, 18(5), 893905. https://doi.org/10.1109/TFUZZ.2010.2051447 
40. Vafamand, N., Mardani, M. M., Khayatian, A., Shasadeghi, M. Non-Iterative SOS-Based Approach for Guaranteed Cost Control Design Of Polynomial Systems with Input Saturation. IET Control Theory \& Applications, 2017, 11(16), 2724-2730. https://doi.org/10.1049/ietcta.2017.0096

41. Vafamand, N. Arefi, M. M., Khayatian, A. Nonlinear System Identification Based on Takagi-Sugeno Fuzzy Modeling and Unscented Kalman Filter. ISA Transactions, 2018, 74, 134-143. https://doi.org/10.1016/j. isatra.2018.02.005

42. Yoshimura, T., Kume, A., Kurimoto, M., Hino, J. Construction of an Active Suspension System of a Quarter Car Model Using the Concept of Sliding Mode Control. Journal of Sound and Vibration, 2001, 239(2), 187-199. https://doi.org/10.1006/jsvi.2000.3117

43. Yoshimura, T., Nakaminami, K., Kurimoto, M., Hino, J. Active Suspension of Passenger Cars Using Linear and Fuzzy-Logic Controls. Control Engineering Practice, 1999, 7(1), 41-47. https://doi.org/10.1016/S09670661(98)00145-2

44. Zare, K. Chaos Synchronization via Adaptive Fuzzy Sliding Mode Controller for a Unified Chaotic System with Uncertainties and External Disturbances. The Mediterranean Journal of Measurement and Control, 2015, 11(2), 387-393
45. Zare, K., Koofigar, H. R. Decentralized Fuzzy-Integral-Sliding Control for a Class of TITO Uncertain Nonlinear Systems with Application to a 2-DOF Helicopter Model. Journal of Theoretical and Applied Mechanics, 2014, 52(4), 959-969. https://doi.org/10.15632/ jtam-pl.52.4.959

46. Zare, K., Koofigar, H. R. Second Order Sliding Mode Control for a Class of MIMO Uncertain Nonlinear Systems with Application to a Quadruple-Tank Process. The Mediterranean Journal of Measurement and Control, 2014, 10(4), 316-323.

47. Zhang, H., Zhang, Y., Yin, C. Hardware-in-the-Loop Simulation of Robust Mode Transition Control for a Series-Parallel Hybrid Electric Vehicle. IEEE Transactions on Vehicular Technology, 2016, 65(3), 1059-1069. https://doi.org/10.1109/TVT.2015.2486558

48. Zhao, F., Dong, M. Qin, Y., Gu, L., Guan, J. Adaptive Neural Networks Control for Camera Stabilization with Active Suspension System. Advances in Mechanical Engineering, 2015, 7(8), 1-11. https://doi. org/10.1155/2015/542364

49. Zhao, M., Wang, S., Wang, H., Mahabaleshwar, U. Darcy-Brinkman Bio-Thermal Convection in a Suspension of Gyrotactic Microorganisms in a Porous Medium. Neural Computing and Applications, 2019, 31(4), 1-7. https://doi.org/10.1007/s00521-017-3137-y 